\title{
24 month outcomes from the Australian National Hand Hygiene Intiative (NHHI)
}

\author{
P Russo', M Cruickshank², ML Grayson ${ }^{1 *}$ \\ From International Conference on Prevention \& Infection Control (ICPIC 2011) \\ Geneva, Switzerland. 29 June - 2 July 2011
}

\section{Introduction / objectives}

The NHHI was implemented in January 2009 to establish a standardized hand hygiene $(\mathrm{HH})$ culture-change program, including the increased use of alcohol-based handrub (ABHR), throughout all Australian hospitals.

\section{Methods}

A multi-modal culture-change program based on the World Health Organization " 5 Moments" program was implemented in all States/Territories, including development of Australian HH guidelines, HHA and Statebased healthcare worker $(\mathrm{HCW})$ training program, data collection and analysis tools. Training to standardize $\mathrm{HH}$ compliance $(\mathrm{HHC})$ auditing $(\geq 90 \%$ internal/external validity) was conducted nationally and a 4 monthly data submission schedule established. Electronic and online data submission capability enhanced efficiency and participation. Outcomes 24 months after NHHI commencement were assessed.

\section{Results}

After 24 months, 521 healthcare facilities from all States/Territories submitted HH compliance data, representing approximately $85 \%$ and $50 \%$ of acute public and private hospital beds, respectively. The overall national (public/private) HHC rate was $68.3 \%$ (95\%CI: 68.1$68.5 \%$ ), with State-based rates (public hospitals) of $60.8 \%$ $>72.6 \%$. National HHC by Moment were: M1: $63.1 \%$, M2: 68.4\%, M3: 79.1\%, M4: 76.0\%, M5: 60.0\%, suggesting that education needs to be focused on improvements in $\mathrm{HH}$ prior to patient contact, especially before performing procedures (M2). Overall HHC among public hospital medical staff was 53.4\% (95\%CI: $52.8 \%$ $>53.9 \%)$.

${ }^{1}$ Hand Hygiene Australia, Heidlelberg, VIC, Australia

Full list of author information is available at the end of the article

\section{Conclusion}

The NHHI has been associated with a rapid national culture-change among Australian HCWs resulting in significantly improved $\mathrm{HHC}$ and a shift to greater use of ABHR. Analysis of NHHI impact on nosocomial disease rates is underway and further improvements in HHC can be expected.

\section{Disclosure of interest}

None declared.

\section{Author details}

${ }^{1}$ Hand Hygiene Australia, Heidlelberg, VIC, Australia. ${ }^{2}$ Australian Commission on Safety and Quality in Health Care, Sydney, Australia.

Published: 29 June 2011

doi:10.1186/1753-6561-5-S6-064

Cite this article as: Russo et al:: 24 month outcomes from the Australian National Hand Hygiene Intiative (NHHI). BMC Proceedings 2011 5(Suppl 6): O64.

Submit your next manuscript to BioMed Central and take full advantage of:

- Convenient online submission

- Thorough peer review

- No space constraints or color figure charges

- Immediate publication on acceptance

- Inclusion in PubMed, CAS, Scopus and Google Scholar

- Research which is freely available for redistribution 